University of Nebraska - Lincoln

DigitalCommons@University of Nebraska - Lincoln

USDA National Wildlife Research Center - Staff Publications
U.S. Department of Agriculture: Animal and Plant Health Inspection Service

December 2002

\title{
Evaluation of lasers to disperse American crows, Corvus brachyrhynchos, from urban night roosts
}

W.P. Gorenzel

University of California, Davis, CA

B. F. Blackwell

USDA/APHIS/WS National Wildlife Research Center, bradley.f.blackwell@aphis.usda.gov

G.D. Simmons

United States Department of Agriculture, Animal and Plant Health Inspection Service, Wildlife Services

T.P. Salmon

University of California, Davis, CA

R.A. Dolbeer

United States Department of Agriculture, Animal and Plant Health Inspection Service, Wildlife Services, National Wildlife Research Center

Follow this and additional works at: https://digitalcommons.unl.edu/icwdm_usdanwrc

Part of the Environmental Sciences Commons

Gorenzel, W.P.; Blackwell, B. F.; Simmons, G.D.; Salmon, T.P.; and Dolbeer, R.A., "Evaluation of lasers to disperse American crows, Corvus brachyrhynchos, from urban night roosts" (2002). USDA National Wildlife Research Center - Staff Publications. 466.

https://digitalcommons.unl.edu/icwdm_usdanwrc/466

This Article is brought to you for free and open access by the U.S. Department of Agriculture: Animal and Plant Health Inspection Service at DigitalCommons@University of Nebraska - Lincoln. It has been accepted for inclusion in USDA National Wildlife Research Center - Staff Publications by an authorized administrator of DigitalCommons@University of Nebraska - Lincoln. 


\section{Evaluation of lasers to disperse American crows, Corvus brachyrhynchos, from urban night roosts}

(Keywords: American crow, bird control, Corvus brachyrhynchos, flock dispersal, hazing, lasers, roosts, urban wildlife)

W. P. GORENZEL*†, B. F. BLACKWELL†, G. D. SIMMONS\$, T. P. SALMON $\dagger$ and R. A. DOLBEER

$\dagger$ Department of Wildlife, Fish, and Conservation Biology, One Shields Ave., University of California, Davis, CA 95616, USA †United States Department of Agriculture, Animal and Plant Health Inspection Service, Wildlife Services, National Wildlife Research Centre, 6100 Columbus Ave., Sandusky, OH 44870, USA

$\S$ United States Department of Agriculture, Animal and Plant Health Inspection Service, Wildlife Services, P. O. Box 255348, Sacramento, CA 95865-5348, USA

\begin{abstract}
American crows (Corvus brachyrhynchos) have a long history of causing agricultural damage in North America. Shooting and bombing at crow night roosts have been employed to reduce such damage. Most roosts were located in rural locations, but in the latter half of the 1900s crows began to roost in urban locations. Urban crow roosts are presently a nationwide problem in the United States. Thousands of crows at a roost create problems for businesses and residents. Improved control techniques are needed. Lasers have been used in Europe to scare and disperse birds but the technique has only recently received formal testing. We treated urban roosts with lasers to determine if crows react to laser light, can be dispersed from roosts, and whether lasers are effective for eliciting roost abandonment. We treated 63 roosts in Woodland, California and recorded the immediate and short-term reactions of crows. We counted crows at five roosts in Davis, California during an 8-day pre-treatment period and then again during a 4-day treatment period to evaluate crow response to laser treatment. Crows reacted to the laser beam. In Woodland $100 \%$ of the crows flew immediately away from $49 \%$ of the treated roosts. Between $50 \%$ to $99 \%$ of all crows flew immediately away at $44 \%$ of the treated roosts. At $84 \%$ of the roosts crows left without vocalizing and at $95 \%$ of the roosts flew directly away without circling overhead. Crows returned to all roosts within $15 \mathrm{~min}$. In Davis there was no difference in the number of crows using roosts during the pre-treatment versus treatment periods. Despite initial dispersal upon treatment, crows reoccupied all treated roosts the same night after treatment. No roosts were abandoned. Therefore, we do not recommend lasers as a stand-alone dispersal tool at urban crow roosts.
\end{abstract}

\section{Introduction}

\subsection{Historical Background}

The American crow (Corvus brachyrhynchos) has been considered an agricultural pest in North America from the days of early European settlers in Virginia and New England (Barrows and Schwarz, 1895). Bounties for crows were offered in most of the eastern USA at one time or another from at least the 1750 s into the late 1800s (Barrows and Schwarz, 1895). The crow's pest reputation prompted major food habits studies by government agencies in the late 1800s and the early 1900s (Barrows and Schwarz, 1895; Kalmbach, 1939). Barrows and Schwarz
(1895) reported damage to corn in the sprouting and milk stages, to apples, and to watermelons. In addition to those crops, Kalmbach (1939) reported damage to shocked corn, wheat, pecans, and peanuts. Kalmbach (1939) also described damage to grain sorghum in Kansas and Oklahoma because of the increased number of crows in that region feeding on latematuring varieties.

\subsection{Roosting Behavior}

American crows roost communally (Goodwin, 1976). Communal roosts are most common during fall and winter months and may contain tens of thousands of birds (e.g. Kalmbach, 1915; Gorenzel and Salmon, 1992). In reporting damage to grain sorghum, Kalmbach (1939) made a link between roosts and agriculture as fields close to crow roosts suffered the most damage. Kalmbach (1939) reported that shooting crews and bombing of entire winter crow roosts were employed to control agricultural damage.

The scientific literature prior to the 1960s mentions only roosts in rural locations and none in urban locations (e.g. Barrows and Schwarz, 1895; Kalmbach, 1915; Emlen Jr., 1938, 1940). Crows apparently began to establish urban roosts in the latter half of the 1900s (e.g. Houston, 1980; Grant, 1973; Gilbert, $1988,1992)$. A nationwide survey of wildlife damage management personnel in the United States supported the concept of a shift from rural roosts to urban roosts by crows (Gorenzel et al., 2000). The survey reported the occurrence of American crow roosts in 110 cities in 28 states (Gorenzel et al., 2000).

With the change in roosting habits, an agricultural wildlife pest became in addition an urban wildlife pest, resulting in new forms of damage. Faecal droppings and regurgitated pellets foul and damage vehicles, buildings, walkways, yards, shrubs and other plantings beneath and near roosts and fueled public health concerns (Gorenzel and Salmon, 1992). The noise from crow vocalizations when leaving a roost in the morning is an additional nuisance for residents. 


\subsection{Population Changes}

Concurrent with a change in roosting sites, Breeding Bird Surveys (BBS) showed significant increases in crow populations from 1966 through 1999 (Sauer et al., 2000). For the entire United States, crow populations increased at $1.3 \% / y r$, equivalent to population increase of nearly 50\% from 1966 through 1999 . In some locations much larger increases were recorded. In the Central Valley of California, a rich agricultural area, BBS recorded a $4.7 \%$ annual increase, a rate that more than quadruples populations from 1966 through 1999.

\subsection{Crop Damage in California}

During this period of changing roost patterns and increasing crow populations, crop damage to California agriculture was a concern. A survey of pistachio growers in the Central Valley identified crows as the primary bird pest and estimated annual crop damage at $\$ 800000$ (Salmon et al., 1986). A similar survey in 1987 of almond growers reported crop losses of $45 \mathrm{~kg} / \mathrm{ha}$ (equivalent to $\$ 198 / \mathrm{ha}$ ) from crows (Hasey and Salmon, 1993). During tests of broadcast distress calls, Salmon et al. (1997) recorded damage levels in almonds up to $\$ 2507 /$ ha, suggesting damage was previously underestimated or the severity of the problem increased. Crows in California also damage a variety of crops including melons, grapes, apricots, pears, prunes, citrus, beans, tomatoes, and peas (Clark, 1994). Although crows now roost primarily in urban areas in California, most crows forage in the agricultural lands surrounding the urban areas. Crows leave and return to roosts along established flyways, with birds concentrated at first and then scattering with distance from the roosts. Croplands along the flyways still face increased damage despite the shift to urban roosts.

\subsection{Control Techniques}

Efforts to disperse crows from night roosts typically rely on pyrotechnics, shooting, or distress calls. These techniques can be successful for small to moderate-scale control efforts (e.g. individual efforts by a resident, group efforts by a neighborhood). However, 12 of 18 large-scale attempts (e.g. covering multiple roosts) using the above techniques were either unsuccessful or only partially successful (Gorenzel et al., 2000). In addition, control efforts such as severe pruning or complete removal of roost trees could be considered as damaging to the urban forest.

New strategies and techniques are needed to disperse crows from roosts on a large scale. Lasers have been available in Europe and are reported by the manufacturers to frighten a variety of European bird species, including corvids (SoucazeSoudat and Ferri, M., 1997). The use of lasers has only recently received attention from researchers in North America (e.g. Glahn et al., 2000; Blackwell et al., 2002). Compared to existing control techniques, lasers possess characteristics which would be useful in an urban setting: light weight, portability, silent operation, long range, no reported injury to birds, and no fire hazard. However, aside from published studies by Glahn et al., (2000) on double-crested cormorants (Phalacrocorax auritus) and by Blackwell et al., (2002) on brown-headed cowbirds (Molothrus ater), European starlings (Sturnus vulgaris), rock doves (Columba livia), Canada geese (Branta canadensis), and mallards (Anas platyrhynchos), little is known about the reaction of most North American bird species to laser light or the most effective application of lasers for different species and locations.

A pilot test of a laser at a rural crow roost in Mansfield, Ohio, USA, in February 2000 indicated that the American crow would be a good candidate for further tests. Crows (approximately 10000) immediately flew from roost trees, with much vocalization, when the laser beam was used on the roost (B. Blackwell, personal observation). After $2 \mathrm{hr}$ of harassment, roost trees were void of crows. However, further treatment on successive nights to determine if birds would abandon roosts could not be undertaken because of aircraft traffic at an adjacent airfield.

Our objective was to examine a potential control technique targeting one aspect of the life cycle of an agricultural and urban pest bird, specifically to: (1) describe and quantify the immediate reactions (e.g., no response or immediate flight) of American crows to laser treatment at urban night roosts in California, and (2) assess the effectiveness of laser treatment in dispersing crows from urban night roosts (e.g., could crow numbers be reduced and would crows abandon treated roosts for $\geqslant 1 \mathrm{night}$ ). We conducted this research under the University of California Davis Animal Care and Use Protocol No. 9380.

\section{Methods}

This study was conducted in the cities of Davis (population 56300) and Woodland (population 44100) in Yolo County, California, USA, in January 2001. We searched along city streets and in shopping centre parking lots for active night roosts. We defined a roost as a tree or group of trees used by crows throughout the night. We identified active roosts based on the presence of fecal droppings, regurgitated pellets, and by direct observation of roosting crows.

We selected five roosts in Davis: four roosts were located along streets on the University of California campus and the fifth in and around the parking lot of a nearby shopping centre. The selected roosts represented a continuum of factors: 1) hosting from $<50$ to $>500$ birds; 2) locations relative to other roosts ranged from isolated to surrounded; 3 ) roosts comprised two to 33 trees; and 4) disturbance was variable (table 1).

With an observer stationed at a fixed vantage point at each roost, we counted crows leaving the Davis roosts in the morning during a 9-day pre-treatment period and a 4-day treatment period. We followed the count procedure of Gorenzel and Salmon (1993) by arriving at roosts prior to the birds' departure and by counting birds both flying out of and into roosts (birds that circled back or flew in from other roosts). We counted at the roosts until all birds had departed, a process that could take up to 60 minutes at the larger roosts. Although planned, we did not count crows during a 5-day post-treatment period (see results below).

We treated roosts using the Desman ${ }^{\mathrm{Nm}}$ Laser (model FL R 005) and the Laser Dissuader (N) (see Glahn et al., 2000; Blackwell et al., 2002 ). The commercially available Desman (Mm is a Class-III B, 5 to $10 \mathrm{~mW}$ He-Ne laser mounted on a rifle stock. The Laser Dissuader ${ }^{\mathrm{TM}}$ is a hand-held, Class-II, 68-mW, diode laser with the appearance of a large flashlight. The optical configuration of the Laser Dissuader ${ }^{\mathrm{Tm}}$ allows the lower Class-Il rating, indicating less hazard (but see Dennis et al., 1989). During pen trails Glahn et al., (2000) reported no ocular damage to double-crested cormorants after direct exposure to 
Table 1. Characteristics of five American crow roosts selected for laser treatment in Davis, California, USA, January 2001

\begin{tabular}{|c|c|c|c|c|c|}
\hline \multirow[b]{2}{*}{ Factor } & \multicolumn{5}{|c|}{ Roost } \\
\hline & 1 & 2 & 3 & 4 & 5 \\
\hline No. of trees ${ }^{a}$ & 7 & 33 & 11 & 2 & 8 \\
\hline Tree type $(s)^{b}$ & Evergreen & Evergreen & Evergreen & Evergreen & $\begin{array}{l}\text { Evergreen and } \\
\text { deciduous }\end{array}$ \\
\hline $\begin{array}{l}\text { Location relative to } \\
\text { other roosts }\end{array}$ & $\begin{array}{c}\text { Isolated, } 1.6 \mathrm{~km} \text { from } \\
\text { roost } 5\end{array}$ & $\begin{array}{c}\text { Isolated, } 0.9 \mathrm{~km} \text { from } \\
\text { roost } 5\end{array}$ & $\begin{array}{l}0.4 \mathrm{~km} \text { from roost } 5 \text {, } \\
0.1 \mathrm{~km} \text { from roost } 4\end{array}$ & $\begin{array}{l}\text { Between roosts } 3 \text { and } \\
5,0.3 \mathrm{~km} \text { from roost } 5\end{array}$ & $\begin{array}{l}\text { Part of the largest roost } \\
\text { in Davis }\end{array}$ \\
\hline $\begin{array}{l}\text { Estimated number of } \\
\text { birds prior to start of } \\
\text { counts }^{c}\end{array}$ & $\sim 40$ & $200-400$ & $\sim 100$ & $\sim 20$ & $>500$ \\
\hline Disturbance $^{d}$ & $\begin{array}{l}\text { Low: on side street with } \\
\text { little traffic and few } \\
\text { pedestrians. }\end{array}$ & $\begin{array}{l}\text { Moderate: next to lit } \\
\text { playing field, parking } \\
\text { lots, and major traffic } \\
\text { artery into campus. }\end{array}$ & $\begin{array}{l}\text { Moderate: next to major } \\
\text { traffic artery and } \\
\text { pedestrian route from } \\
\text { campus to dormitories. }\end{array}$ & $\begin{array}{l}\text { Low: on major traffic } \\
\text { artery but few } \\
\text { pedestrians and no } \\
\text { parking activities. }\end{array}$ & $\begin{array}{l}\text { High: located in busy } \\
\text { parking lot of shopping } \\
\text { mall with many } \\
\text { pedestrians, and next } \\
\text { to central traffic artery } \\
\text { in Davis. }\end{array}$ \\
\hline
\end{tabular}

${ }^{a}$ Number of trees that were included in the morning crow counts.

${ }^{\mathrm{b}}$ Evergreen trees were cork oak (Quercus suber) and pines (Pinus spp.).

${ }^{\mathrm{c}}$ Bird estimates based on number of trees occupied, relative amounts of droppings and pellets on the ground, and observations during scouting trips.

${ }^{d}$ Disturbance ratings based on estimates of traffic volume on the closest street(s), vehicle parking activities, and occurrence of pedestrians during the evening as described in Gorenzel and Salmon (1995).

the Desman ${ }^{\text {(im) }}$ Laser from distances as small as $1 \mathrm{~m}$. In addition, Glahn et al., (2000) judged both lasers equally effective in treating double-crested cormorant roosts. However, Blackwell et al., (2002) cautioned that the effectiveness of lasers used as avian dispersal tools is species- and contextspecific.

We treated the Davis roosts with lasers for four nights with the Desman ${ }^{\mathrm{Im}}$ Laser and the Laser Dissuader ${ }^{\mathrm{TM}}$. All treatments began after $1900 \mathrm{hr}$, well after sunset and the arrival of the birds at the roosts. We treated each tree in a roost by standing to one side or under the canopy of the roost tree, starting the laser beam at the base of the tree trunk and then working up the trunk into the canopy, or by sweeping the laser beam at the start back and forth through the canopy. Pilot tests in Ohio indicated no apparent difference in crow response regardless of the operator's location (under or next to the canopy) or initial target (trunk or canopy), thus we considered the firing procedures to be one treatment. We moved to the next tree when it appeared all birds had left the treated tree. During the treatment periods which varied from 15 to 60 minutes depending on the roost, observers positioned to the sides of the roosts advised the laser operator if any birds returned to the roost trees. When we reached the last tree in a roost, we retreated trees if crows had returned or we departed to treat the next roost if no birds had returned. We also treated trees immediately next to roosts 3 to 5 as these trees were occupied by crows. We did not treat trees around roosts 1 and 2 as either none were present or they were not occupied. To examine the changes in crow numbers at roosts we restricted analyses to descriptive statistics (e.g., $\bar{x}$, $\mathrm{SD}$ ) and in particular 95\% confidence intervals (see Johnson, 1999:769 regarding the value of confidence intervals vs. $P$ values).

We used roosts in Woodland to assess the immediate and short-term reactions of crows to the laser. On 13, 23, and 29 January 2001 we used the Dissuader Laser ${ }^{\mathrm{Am}}$ to treat roost trees as described above. For each roost we recorded tree type (deciduous or evergreen), time of treatment, and the crows' behaviour. We recorded the crows' immediate reaction to the laser: (1) percentage leaving the roost $(0 \%,>0 \%$ but $<50 \%$, $\geqslant 50 \%$ but $<100 \%$, or $100 \%$ ), (2) vocalizations (none, some [e.g. one or two birds briefly calling], much [e.g. the majority of birds giving assembly and scolding calls as described by Chamberlain and Cornwell \{1971\}]), (3) flight behaviour (flew directly away or circled overhead), (4) whether crows returned to the roost, and $(5)$ the time elapsed until retum $(\leqslant 1 \mathrm{~min},>1$ to $5 \mathrm{~min},>5$ to $10 \mathrm{~min}$, and $>10$ to $15 \mathrm{~min}$ ).

\section{Results}

\subsection{Short-term responses to laser treatment}

We treated 63 trees in Woodland; 43 trees (68\%) were deciduous and 20 trees (32\%) were evergreen. At all roosts crows reacted to the laser; in nearly half $(49 \%)$ of the treatments all crows responded by immediately flying out of the roosts (table 2). At $44 \%$ of the roosts the majority of crows ( $\geqslant 50 \%$ but $<100 \%$ ) flew out immediately. In all cases crows that did not take flight immediately eventually left the roosts as treatment continued. At $84 \%$ of the roosts the crows left without vocalizing and at $95 \%$ of the roosts the crows flew directly away without circling overhead. In all cases crows returned to the roosts within a 15-minute period. We found no difference in the crows' responses based on tree type, except with regard to immediate response to the laser. Fewer crows took flight from evergreen $(63 \%)$ than deciduous trees $(20 \%)$, likely because of the density of cover vegetation (table 2).

\subsection{Multi-night treatment of roosts}

We conducted 4 to 7 counts at each roost in Davis during the pre-treatment period. The average number of crows during the pre-treatment period ranged from 8 birds/night at roost 4 to 
$>680$ birds/night at roost 5 (table 3 ). After the first night of treatment on 22 January, counts the next morning indicated more crows at four of five roosts than the previous morning (table 3). All roosts were reoccupied after each night of treatment. The average number of crows increased from the

Table 2. The number (percentage in parentheses) of laser-treated urban American crow roosts in Woodland, California, USA, and responses of crows to laser treatment during January 2001

\begin{tabular}{|c|c|c|c|}
\hline Response & All roosts & $\begin{array}{c}\text { Deciduous } \\
\text { trees }\end{array}$ & $\begin{array}{c}\text { Evergreen } \\
\text { trees }\end{array}$ \\
\hline \multicolumn{4}{|c|}{ Immediate response to the laser: } \\
\hline None flew away & $0(0)$ & $0(0)$ & $0(0)$ \\
\hline $100 \%$ flew away & $31(49)$ & $27(63)$ & $4(20)$ \\
\hline $50-99 \%$ flew away & $28(44)$ & 14 (33) & $14(70)$ \\
\hline$<50 \%$ flew away & $4(6)$ & $2(5)$ & $2(10)$ \\
\hline \multicolumn{4}{|l|}{ Vocalization: } \\
\hline No calls & $53(84)$ & $38(88)$ & $15(75)$ \\
\hline Some calling $^{a}$ & $7(11)$ & $3(7)$ & $4(20)$ \\
\hline Much calling ${ }^{b}$ & $3(5)$ & $2(5)$ & $1(5)$ \\
\hline \multicolumn{4}{|l|}{ Flight: } \\
\hline Flew directly away & $60(95)$ & $41(95)$ & $19(95)$ \\
\hline Circled over roost & $3(5)$ & $2(5)$ & $1(5)$ \\
\hline Returned to roost ${ }^{c}$ & $55(100)$ & $37(100)$ & $18(100)$ \\
\hline \multicolumn{4}{|l|}{ Minutes till return: ${ }^{c}$} \\
\hline$\leqslant 1 \min$ & $14(25)$ & $12(32)$ & $2(11)$ \\
\hline$>1$ to $5 \mathrm{~min}$ & $11(20)$ & $5(14)$ & $6(33)$ \\
\hline$>5$ to $10 \mathrm{~min}$ & $18(33)$ & $12(32)$ & $6(33)$ \\
\hline$>10$ to $15 \mathrm{~min}$ & $12(22)$ & $8(22)$ & $4(22)$ \\
\hline
\end{tabular}

${ }^{a}$ One or two birds briefly calling.

${ }^{\mathrm{b}}$ The majority of birds giving assembly and scolding calls as described by Chamberlain and Cornwell (1971).

${ }^{\mathrm{c}}$ The return of crows was not recorded at eight roosts (six deciduous and two evergreen trees). pre-treatment to the treatment period at roosts $1(2.5 \mathrm{X})$ and 3 (1.9X). The average number of crows decreased at roost 2 , however $>200$ birds used the roost on two nights during the treatment period. The mean number of crows at each roost during the treatment period was either contained within the $95 \%$ Cls of the pretreatment period means at three roosts (roosts 2, 4 , and 5) or had higher values at two roosts (roosts 1 and 3 ), suggesting no treatment effect at any roost. We canceled the planned post-treatment counts due to the continued use of the roosts and the absence of any decrease in crow numbers after treatment.

Crow behaviour upon treatment of the Davis roosts was generally similar to that observed at the roosts in Woodland. The majority of crows immediately flew directly away from the treated roosts with little or no vocalization. At roosts 2 and 5 the birds returned within minutes or flew from one end of the roost to the other in response to the laser. At roosts 1, 3, and 4 it appeared that the crows vacated the roosts upon treatment as we did not observe any returning birds during the evenings of treatment. However, crows did return to the roosts at some time during the night as evidenced by birds exiting the next morning. At roost 5 we noted that a small number $(<5 \%)$ of crows did not fly away, even when they were individually targeted and "struck" by the laser beam for periods of 5 to $15 \mathrm{sec}$. Crows at roost 5 were more difficult to disperse, possibly due to the dense canopies of the pine trees that blocked the laser beam.

\section{Discussion}

Crows perceived and reacted to the laser beam, in most cases by immediately leaving the roost. However, there was no lasting effect as crows returned in most cases within a few minutes and reoccupied the roosts. No roost was abandoned for even 1 night, nor did crow numbers decrease at the treated roosts. The response of crows to the laser was comparable to the temporary disturbance caused by loud buses, trucks or pedestrians passing by a roost.

Table 3. Daily and mean number of American crows leaving five roosts (treated the previous night with lasers) during morning counts in Davis, California, USA, January 2001

\begin{tabular}{|c|c|c|c|c|c|c|}
\hline \multirow[b]{2}{*}{ Period } & \multirow[b]{2}{*}{ Date } & \multicolumn{5}{|c|}{ Roost } \\
\hline & & 1 & 2 & 3 & 4 & 5 \\
\hline \multirow[t]{8}{*}{ Pre-treatment } & 14 January & $-^{a}$ & 447 & - & - & - \\
\hline & 16 January & - & - & - & - & 939 \\
\hline & 17 January & 25 & 74 & 101 & 5 & - \\
\hline & 18 January & 16 & 61 & 75 & 13 & 746 \\
\hline & 19 January & 39 & 84 & 55 & 7 & 495 \\
\hline & 20 January & 52 & 410 & 60 & - & 720 \\
\hline & 21 January & - & 526 & 171 & - & - \\
\hline & 22 January & 42 & 223 & 130 & 7 & 509 \\
\hline$\overline{\times}(\mathrm{SD})$ & & $35(14)$ & 261 (198) & 99 (45) & $8(4)$ & 682 (185) \\
\hline $95 \% \mathrm{Cl}$ & & 17 to 52 & 78 to 444 & 51 to 146 & 2 to 14 & 452 to 911 \\
\hline \multirow[t]{4}{*}{ Treatment $^{\mathrm{b}}$} & 23 January & 77 & 290 & 275 & 6 & 1030 \\
\hline & 24 January & 54 & 35 & 73 & 5 & 419 \\
\hline & 25 January & 133 & 128 & 209 & 3 & 460 \\
\hline & 26 January & - & 211 & - & - & 1181 \\
\hline$\overline{\times}(\mathrm{SD})$ & & $88(41)$ & $166(110)$ & $186(103)$ & $5(2)$ & 772 (390) \\
\hline
\end{tabular}

${ }^{a}$ Indicates counts were not undertaken on that date at the indicated roost.

${ }^{\mathrm{b}}$ Treatment began on the evening of 22 January 2001 and continued every evening through 25 January 2001 , except for roosts 1 , 3 , and 4 which were not treated on 25 January 2001. 
The behaviour of crows upon exiting a roost treated by the laser differed from that described by Gorenzel and Salmon (1993) of crows at roosts treated with a crow distress call. Crows responding to a broadcast distress call immediately flew out of the roost, circled overhead giving assembly and scolding calls. Crows from other nearby roosts flew in to join the circling, calling crows. The circling and calling continued as long as the distress call was played. When the broadcasts ended, the crows dispersed and did not return to the treated roost. In contrast during our study, crows at laser-treated roosts did not vocalize, circle overhead, or attract crows from other roosts, and returned to the treated roosts. We suggest that the distress call, which has biological meaning to the crows, and the calling and mobbing by crows overhead, warn that a predator is present and that the treated roost is not safe. None of these components were present or produced after laser treatment at urban crow roosts. The rapid return to the laser-treated roosts suggests the crows perceived the treated roosts as safe. The laser beam produced a startle reaction comparable to that produced by a sudden, loud noise, but imparted no threat sufficient to cause desertion of a roost.

\section{Management Implications}

Laser treatment, as applied following our treatment scenario, was not effective in dispersing crows from urban night roosts. We cannot recommend lasers as a stand-alone dispersal tool at urban crow roosts based on the poor results and the costs of the lasers $(\$ 5,600-\$ 7,500)$. However, lasers may have a role under a different application scenario or when applied with other devices. The bird control concept of initiating control measures at the first sign of damage and before the birds have developed a well-established habit (e.g. using the same roost) is generally well accepted. In addition, control actions at roosts (e.g. shooting or scaring) are typically implemented as the birds fly into the roost in an attempt to prevent the birds from landing at the roost. We departed from these conventions. In our application of lasers we waited until the birds had settled into the roosts before initiating treatment. In addition, the birds had been using the roosts for at least 2 to 3 months prior to treatment. Application of the lasers when the birds begin entering the roosts for the evening and at the start of the roosting season might be effective, but remains untested. Lasers also might be used to enhance other techniques. For example, a broadcast distress call only disperses crows from a limited area around the treated roost. The concurrent use of a laser on distant roosts might extend the area of effectiveness for the distress calls.

\section{Acknowledgments}

We thank Barthell Joseph III of Reed-Joseph International Company, Greenville, Mississippi, USA, for use of the Desman(III) Laser, and SEA Technology, Inc., Albuquerque, New Mexico, USA, for use of the Dissuader Laser $\mathrm{MM}$. We thank Edward A. Dochtermann, Jack Parriott, Brett G. Dunlap, and Glenn E. Bernhardt for participating in the morning bird counts or the evening roost treatments in Davis. Kristina L. Norberg assisted with fieldwork in Woodland.

\section{References}

BARROWS, W. B., and SCHWARZ, E. A., 1895. The common crow of the United States. United States Department of Agriculture, Division of Ornithology and Mammalogy, Bulletin No. 6 (Washington, D. C.: Government Printing Office), $98 \mathrm{pp}$.

BLACKWELL, B. F., BERNHARDT, G. E. and DOLBEER, R. A., 2002. Lasers as non-lethal avian repellents. Journal of Wildlife Management, 66, 250258.

CHAMBERLAIN, D. W. and CORNWELL, G. W., 1971. Selected vocalizations of the common crow. Auk, 88, 613-634.

CLARK, J. P., 1994. Vertebrate pest control handbook. Fourth ed. (Sacramento, California: California Department of Food and Agriculture), 350 pp.

DENNIS, J. T., HARRISON, J. T., WALLACE, W. E., THOMAS, R. J. and CORA, S. R., 1999. Visual effects assessment of the Dissuader laser illuminator. United States Air Force Research Laboratory Report. AFRLHE-BR-TR-1999-0179.

EMLEN JR., J. T., 1938. Midwinter distribution of the American crow in New York state. Ecology, 19, 264-275.

EMLEN JR., J. T., 1940. The midwinter distribution of the crow in California. Condor, 42, 287-294.

GILBERT, B., 1988. Goodbye, Hello. Sports Illustrated, 69, 108-112, 114, 116 , 118, $120-122$.

GILBERT, B., 1992. Crows fly far and wide, but there's no place like home. Smithsonian, 23, 101-111.

GLAHN, J. F., ELLIS, G., FIORANELLI, P. and DORR, B. S., 2000. Evaluation of moderate- and low-powered lasers for dispersing double-crested cormorants from their night roosts. Proceedings Eastern Wildlife Damage Management Conference, 9, 34-45.

GOODWIN, D., 1976. Crows of the world (Ithaca, New York: Cornell University Press) $354 \mathrm{pp}$.

GORENZEL, W. P. and SALMON, T. P., 1992. Urban crow roosts in California Vertebrate Pest Conference, 15, 97-102.

GORENZEL, W. P. and SALMON, T. P., 1993. Tape-recorded calls disperse American crows from urban roosts. Wildlife Society Bulletin, 21, 334-338.

GORENZEL, W. P. and SALMON, T. P., 1995. Characteristics of American crow urban roosts in California. Journal of Wildlife Management, 59, 638645.

GORENZEL, W. P., SALMON, T. P., SIMMONS, G. D., BARKHOUSE, B. and QUISENBERRY, M. P., 2000. Urban crow roosts - a nationwide phenomenon? Proceedings Eastern Wildlife Damage Management Conference, $\mathbf{9}$, $158-170$.

GRANT, G., 1973. Crows converting to lives of city slickers. Los Angeles Times Orange County part XI, 26 August, 1, 8-9.

HASEY, J. and SALMON, T. P., 1993. Crow damage to almonds increasing: no foolproof solution in sight. California Agriculture, 47, 21-23.

HOUSTON, C. S., 1980. Fall crow roosts in residential Saskatoon. Blue Jay, $\mathbf{3 8}$, $42-43$.

JOHNSON, D. H., 1999. The insignificance of statistical significance testing. Journal of Wildlife Management, 63, 763-772.

KALMBACH, E. R., 1915. Winter crow roosts. United States Department of Agriculture Yearbook (Washington, D. C.: Government Printing Office), pp. 83-99.

KALMBACH, E. R., 1939. The crow in its relation to agriculture. United States Department of Agriculture Farmers' Bulletin No. 1102 (Washington, D. C.: Government Printing Office), $22 \mathrm{pp}$.

SALMON, T. P., CRABB, A. C. and MARSH, R. E., 1986. Bird damage to pistachios. California Agriculture, 40, 5-8.

SALMON, T. P., GORENZEL, W. P. and FORD, W. K., 1997. Test of a taped alarm call to reduce crow damage in almonds. Final Report to California Department of Food and Agriculture Contract No. 96-0486, Sacramento, California. $37 \mathrm{pp}$.

SAUER, J. R., HINES, J. E., THOMAS, I., FALLON, J. and GOUGH, G., 2000. The North American Breeding Bird Survey, Results and Analysis 19661999. Version 98.1, Unites States Geological Service, Patuxent Wildlife Research Center, Laurel, MD, USA.

SOUCAZE-SOUDAT, J. D. and FERRI, M. A means of scaring birds: the laser gun, description and applications to cormorants and other birds. Desman S. A. R. L., France, and Office of Wildlife Protection and Regulation of Hunting and Fishing, Italy, 1997. 